
S. A. Pfister
A. Deckart
S. Laschke
S. Dellas
U. Otto
C. Buitrago
J. Roth
W. Wiesner
G. Bongartz
T. C. Gasser

Published online: 21 June 2007

(C) Springer-Verlag 2007

The online version of the original article can be found at http://dx.doi.org/10.1007/s00330003-1937-1.

S. A. Pfister · S. Dellas · U. Otto ·

C. Buitrago · W. Wiesner - G. Bongartz

Department of Radiology,

University Hospital,

Petersgraben 4,

4031 Basel, Switzerland

\author{
A. Deckart - S. Laschke - T. C. Gasser \\ Department of Urology, \\ University Hospital, \\ Petersgraben 4, \\ 4031 Basel, Switzerland \\ J. Roth \\ Department of Radiologic Physics, \\ University Hospital, \\ Petersgraben 4, \\ 4031 Basel, Switzerland
}

\section{S. A. Pfister $(\square)$}

Medical Imaging Lucerne,

Theaterstrasse 7 ,

6003 Lucerne, Switzerland

e-mail: pfister@centralnet.ch

Tel.: +41-41-2272030

Fax: +41-41-2272031

\title{
Unenhanced helical computed tomography vs intravenous urography in patients with acute flank pain: accuracy and economic impact in a randomized prospective trial
}

"In the article entitled "Unenhanced helical computed tomography vs intravenous urography in patients with acute flank pain: accuracy and economic impact in a randomized prospective trial" by Dr. Pfister unfortunately a formal error in the numbers listed in table 1 has occurred: the study has not detected stones in 159 percent of patients as published but in 159 patients out of 228 yielding a detection percentage of $70 \%$." 